\title{
Hunter syndrome presenting as heart failure: A case report
}

\author{
Asutosh Biswas, Prajowl Shrestha
}

\begin{abstract}
Introduction:

Hunter

syndrome

(Mucopolysaccharidosis type II, MPS II) is a genetic disorder associated with deficiency of lysosomal enzyme iduronate-2-sulfatase and impairment of glycosaminoglycans (GAGs) metabolism. Hunter syndrome is well described in medical literature but less is known about heart failure. We are presenting a rare case of Hunter-syndrome with heart failure. Case Report: A 17-year-old boy presented to emergency department with chief complaint of dyspnea on exertion for last seven days. He also had history of progressive abdominal swelling since five years of age. On examination, he was tachypneic with raised jugular venous pressure and bilateral pitting pedal edema. His head was dolicocephalic in shape with coarse facial features. His abdomen was distended with hepatosplenomegaly and an umbilical hernia. He has one younger brother with similar clinical profile and one normal younger sister. Suspecting mucopolysaccharidosis, we performed a skeletal survey. A lateral X-ray of the skull showed an enlarged and J-shaped sella turcica. Patient's and his brother's enzyme assays for iduronate-2-sulfatase were markedly
\end{abstract}

Asutosh Biswas ${ }^{1}$, Prajowl Shrestha²

Affiliations: ${ }^{1} \mathrm{MD}$, Additional Professor, Department of Medicine, All India Institute of Medical sciences, New Delhi, Delhi, India; ${ }^{2} \mathrm{MD}$, Resident, Department of Medicine, All India Institute of Medical sciences, New Delhi, Delhi, India Corresponding Author: Asutosh Biswas, Additional Professor, Department of Medicine, Room No.: 4079, All India institute of Medical Sciences, New Delhi, India 110029; Phone: +919968304243; E-mail: asudelhi@gmail.com

Received: 27 August 2012

Accepted: 07 December 2012

Published: 01 June 2013 low. Based on the clinicoradiological and enzyme assay diagnosis of Hunter syndrome (MPS II) was made. Conclusion: Various clinical and radiological features are typical of MPS II. A detailed clinical evaluation and radiological investigations help in diagnosis of MPS II. The enzyme assay is required to confirm the diagnosis.

Keywords: Mucopolysaccharidosis, Hunter syndrome, Iduronate-2-sulfatase

$$
* * * * * * * * *
$$

Biswas A, Shrestha P. Hunter's syndrome presenting as heart failure: A case report. International Journal of Case Reports and Images 2013;4(6):321-325.

$$
* * * * * * * * *
$$

doi:10.5348/ijcri-2013-06-322-CR-7

\section{INTRODUCTION}

Mucopolysaccharidosis (MPS) is a group of autosomal recessive metabolic disorders caused by the absence or malfunctioning of the lysosomal enzymes needed to break down the glycosaminoglycans (GAGs) [1]. GAGs are long chains of sugar carbohydrates in each cell that help build bone, cartilage, tendons, corneas, skin and connective tissues. Hunter syndrome, a MPS II is a rare, $\mathrm{X}$-linked disorder caused by a deficiency of the lysosomal enzyme iduronate-2-sulfatase, which catalyzes a step in the catabolism of glycosaminoglycans [1]. It is one of the most common MPS, with an estimated prevalence of 1 in 170,000 male live births [2-4]. In patients with Hunter syndrome, glycosaminoglycans accumulate within the tissues and organs, contributing to the signs and symptoms of the disease. Common clinical presentation includes facial dysmorphism, hepatosplenomegaly, joint stiffness and 
contractures, pulmonary dysfunction, myocardial enlargement and valvular dysfunction, neurological involvement and excess urinary GAGs excretion [5]. Diagnosis of this disease is based on the compatible clinico radiological profile with serum enzyme assay and urinary tests for excess GAGs. Enzyme replacement therapy has emerged as a new treatment for mucopolysaccharidosis disorders, including Hunter syndrome. We report this case of MPS type II because of its rarity and features of acute decompensated heart failure as a presenting feature. The purpose of presenting this case is to highlight the distinctive clinical features of Hunter syndrome.

\section{CASE REPORT}

A 17-year-old boy from Madhya Pradesh (India) presented to emergency department with chief complaints of dyspnea on exertion New York Heart Association (NYHA) class IV for last seven days. He had history of progressive increase in shortness of breath since last six months associated with swelling of both the limbs. He also had a history of progressive abdominal swelling since five years of age, excessive snoring with disturbed sleep associated with excessive day time sleepiness since nine years of age. There was no history of chest pain, abdominal pain, fever, constipation, diarrhea, vomiting, bleeding, jaundice, seizure, weight loss or loss of appetite or of consciousness. His bowel and bladder habit was normal. He was deaf and dumb since childhood. He has one younger brother with similar clinical profile and one normal younger sister. He was a product of nonconsanguineous marriage and was delivered after full term normal pregnancy. His perinatal period was uneventful. Family pedigree chest of the patient is shown in Figure 1.

On examination, the patient's head was dolicocephalic in shape, with a circumference of $58 \mathrm{~cm}$. $\mathrm{He}$ had a depressed and flat nasal bridge, flaring nostrils, large tongue, a short neck, coarse facial features, small stubby fingers with flexion of the distal interphalangeal joint (Figure 2A-2B). Anthropometric examination showed him to be severely stunted (height of $114 \mathrm{~cm}$ ) without wasting. His fundus appeared normal. His abdomen was soft, distended with an umbilical hernia. His liver was $14 \mathrm{~cm}$ below the right costal margin in the mid-clavicular line, with a firm, sharp margin and a smooth surface with a span of 16 $\mathrm{cm}$. His spleen was $4 \mathrm{~cm}$ below the left costal margin in the mid-clavicular line. There were diffuse inspiratory crepitations all over the lung field. His heart had a grade $3 / 6$ non-radiating systolic murmur in the mitral and tricuspid area. Suspecting MPS, we performed a skeletal survey. Anteroposterior and lateral X-rays of the skull showed an enlarged and J-shaped sella turcica (Figure 3 ). The bones of the skull and sutures appeared normal for his age. Anteroposterior and lateral X-rays of the dorsolumbar spine showed antero inferior beaking at L2. X-rays of both hands showed his phalanges and metacarpals to be widened with proximal pointing (Figure 4). The remaining bones and joints under view appeared normal. X-ray of chest showed gross cardiomegaly with widened anterior end of ribs (Figure 5).

Two-dimensional ECHO showed thickened valves with mild mitral, aortic and tricuspid regurgitation. Both the ventricles were hypertrophied. There was mild biventricular dysfunction with left ventricular ejection fraction of $45 \%$.

Otolaryngology (ENT) evaluation revealed adenoid hypertrophy and edematous arytenoids. Pure tone

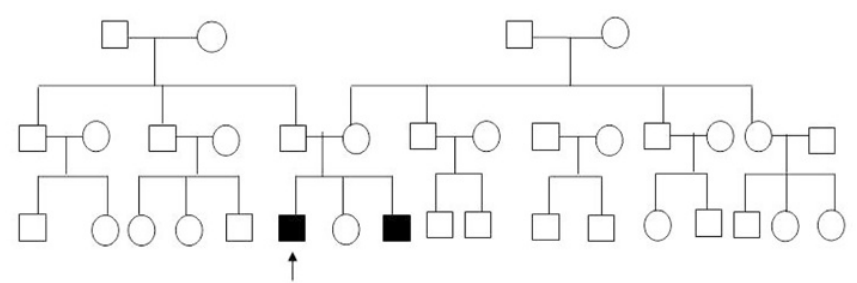

Figure 1: Family pedigree chart of the patient, arrow showing the patient.
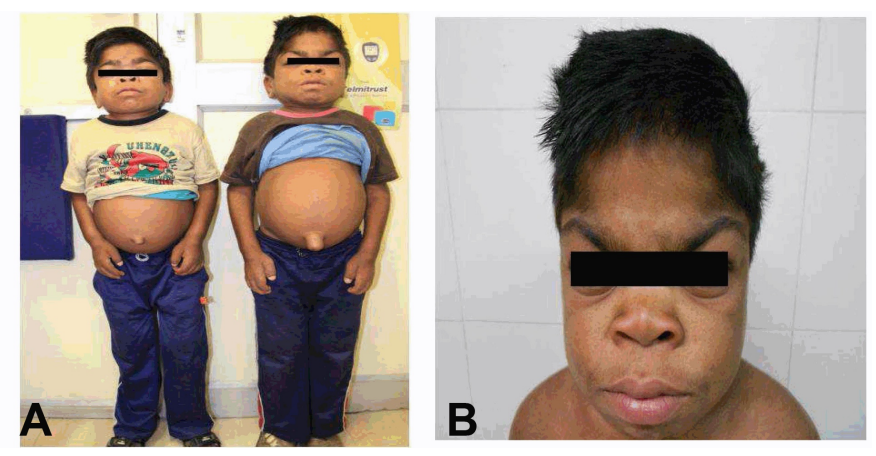

Figure 2: (A) Patient with hunter's syndrome with his brother showing coarse facial features, flat nasal bridge and umbilical hernia, (B) Patient's hand with small stubby fingers with flexion deformity of the distal interphalangeal joint.

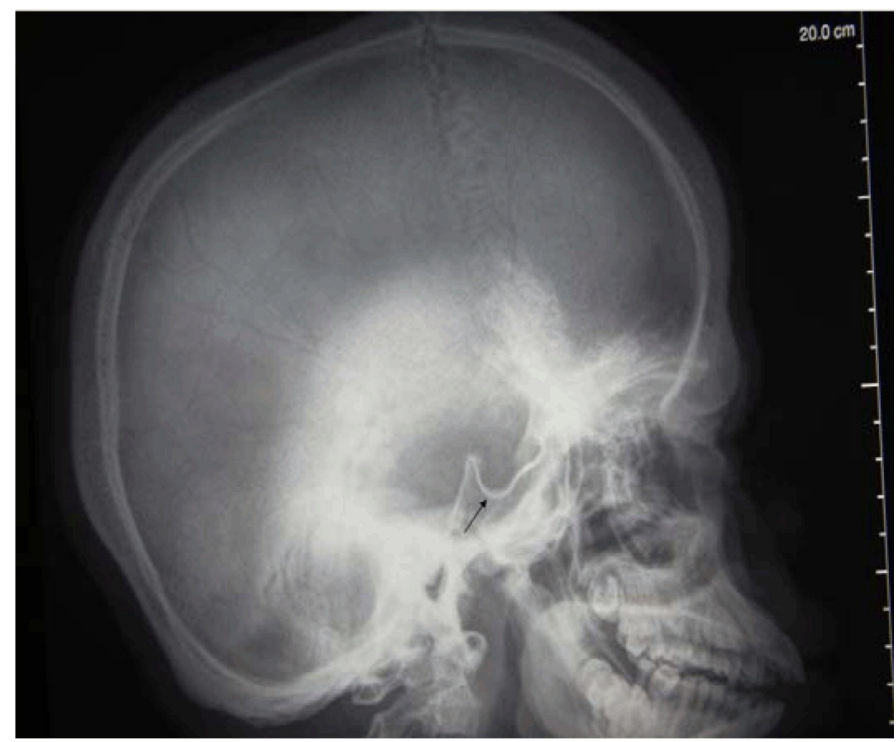

Figure 3: Lateral X-ray of skull of patient showing prominent J-shaped sella turcica. 
audiometry showed mixed conductive and sensorineural hearing deafness.

Non-contrast computed tomography (NCCT) of head was done which showed dolichocephalic head with mild ventricular enlargement. Polysomnography was done in view of his excessive snoring and day time sleepiness. However, the polysomnography was normal with Apnea-Hypopnea index of 4.7. Enzyme assay for Iduronate-2-sulfatase was done for both the brothers. The Iduronate-2- sulfatase levels were markedly low in both the brothers, the levels were $0.19 \mathrm{nmol} / 4 \mathrm{hr} / \mathrm{mg}$ in patient and $0.34 \mathrm{nmol} / 4 \mathrm{hr} / \mathrm{mg}$ in his brothers. Normal range of this enzyme is $>30 \mathrm{nmol} / 4 \mathrm{hr} / \mathrm{mg}$ (Table 1 and Table 2). The positive enzyme assay confirmed our diagnosis of Hunter syndrome (MPS II).

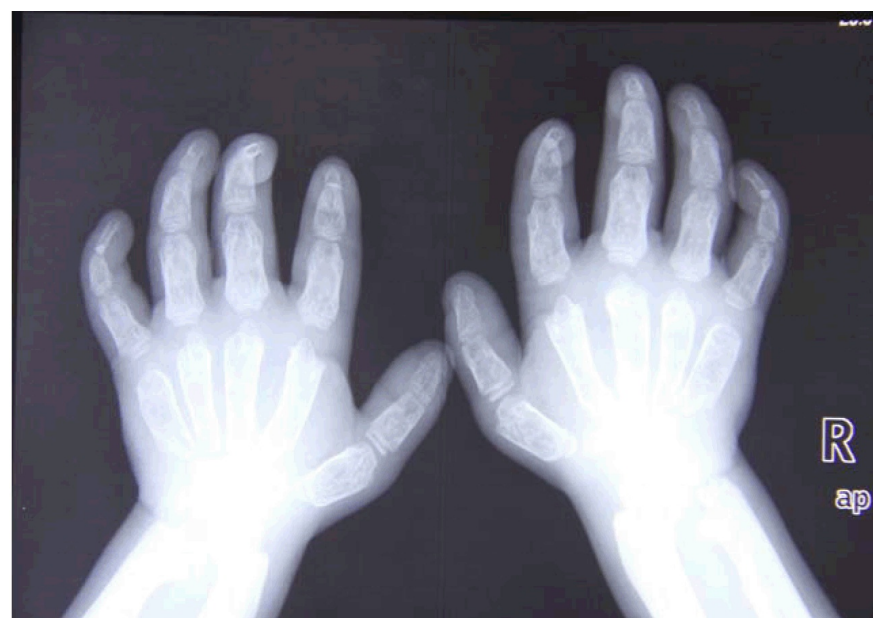

Figure 4: X-rays of both hands showing widened phalanges and metacarpals with proximal pointing.

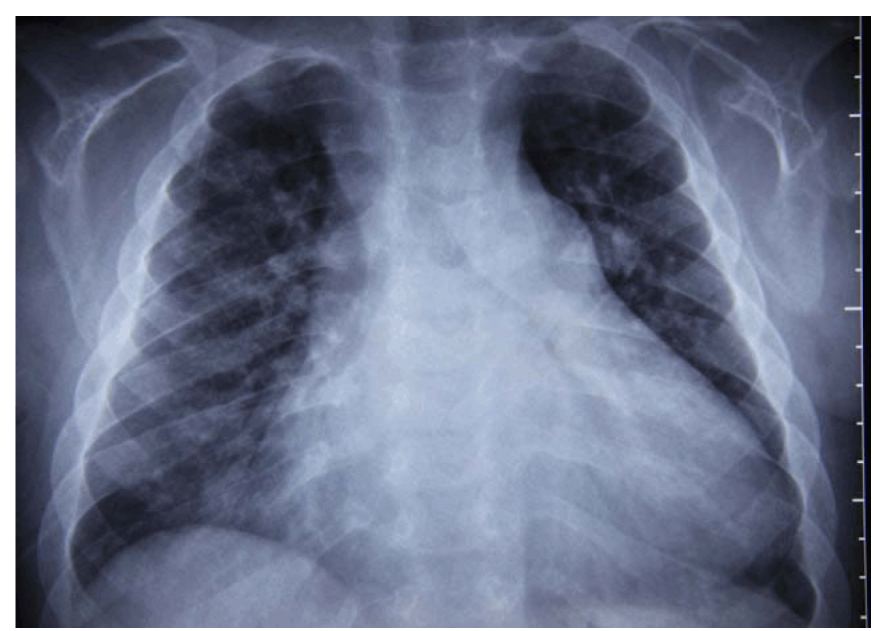

Figure 5: Chest X-ray showing the gross cardiomegaly with widened anterior end of ribs.

\section{DISCUSSION}

In our case all the clinical features such as short stature, a large head, organomegaly, a depressed nasal bridge, a short neck, coarse facial features, small stubby fingers, mild mental retardation with normal intelligence; and radiological features such as a Jshaped sella turcica, beaking of vertebrae, proximal tapering of metacarpal bones and tapering of the posterior ends of ribs (paddle and/or spatulated ribs) as well as his developmental history were all suggestive of MPS II.

Mucopolysaccharidosis was first described by Charles Hunter, a Canadian physician, who in 1917 described a rare disease found in two brothers [6]. Mucopolysaccharidosis is a group of inherited diseases characterized by defective lysosomal enzymes responsible for the degradation of mucopolysaccharides, which are major components of intercellular connective tissue. This leads to an accumulation of incompletely degraded mucopolysaccharides in the lysosomes which affect various body systems through enzymatic activity [7].

All MPS are autosomal recessive, except Hunter syndrome which is X-linked recessive. In affected individuals, undegraded or partially degraded GAG accumulates within the lysosomes and is excreted in excess in the urine. The accumulation of GAG within the lysosomes is responsible for the clinical manifestation of this disorder [8]. Mucopolysaccharidosis type II or Hunter syndrome is rare and is caused by a deficiency of iduronate-2-sulfatase as described by Neufeld in 1987 [9]. Hunter syndrome is one of the most common MPS with a prevalence of one in 170,000 male live births [2-4]. Patients typically appear normal at birth. In the severe form, clinical features appear between two and four years of age while in the mild form the clinical features appear in the second decade of life. In the severe form there is severe mental retardation and loss of skills. Death usually occurs in the first or second decade of life and the main cause of death is obstructive airway disease or cardiac failure [1]. In the milder form there is mild mental retardation but intelligence is normal, stature is near normal and clinical features are less obvious and progress very slowly. Diagnosis is usually made in the second decade of life. Death usually occurs in the fourth decade and the main cause of death is cardiac failure.

Diagnosis of the disease is usually made by clinical presentation and skeletal survey. The common clinical presentations are a large head (dolichocephalic), short

Table 1: Enzyme assays of patient with Hunter syndrome.

\begin{tabular}{llll}
\hline Enzymes & Patient's value & Normal range & Normal control \\
\hline
\end{tabular}

Iduronate-2- sulphatase

0.19

547.09 $\geq 30 \mathrm{nmol} / 4 \mathrm{hr} / \mathrm{mg}$

$213.89 \mathrm{nmol} / 4 \mathrm{hr} / \mathrm{mg}$ 
Table 2: Enzyme assay of patient's brother with Hunter's syndrome.

\begin{tabular}{lllr}
\hline Enzymes & Patient's value & Normal range & Normal control \\
\hline Iduronate-2sulphatase & 0.34 & $\geq 30 \mathrm{nmol} / 4 \mathrm{hr} / \mathrm{mg}$ & $213.89 \mathrm{nmol} / 4 \mathrm{hr} / \mathrm{mg}$ \\
$\beta$-Galactosidase & 567.77 & $\geq 80 \mathrm{nmol} / \mathrm{hr} / \mathrm{mg}$ & $597.88 \mathrm{nmol} / \mathrm{hr} / \mathrm{mg}$
\end{tabular}

stature, mental retardation, coarse facial features, a protuberant abdomen, a broad nose with flared nostrils, large jaws, hypotonia and a large tongue which becomes apparent between two and four years of age, and these clinical features were present in our case. Other clinical features include upper respiratory tract infection, valvular heart disease leading to right and left ventricular hypertrophy and heart failure, chronic diarrhea, enlarged liver and spleen, umbilical as well as inguinal hernia, poor vision and hearing loss caused by both conductive and sensorineural deficits. A communicating hydrocephalus is a common finding and can lead to severe manifestation of neurological signs. Our patient had most of these clinical manifestations. Besides this, our patient presented to us with features of acute decompensation of biventricular failure which responded to diuretics and other supportive measures.

Analysis of GAGs (heparan and dermatan sulphates) is a screening test for MPS II [1]. The presence of excess heparan and dermatan sulphates in the urine is evidence of MPS I, MPS II or MPS VII. Confirmatory diagnosis is by enzyme assay in leukocytes, fibroblasts or dried blood spots and plasma sample. Absent or low enzyme activity in males is diagnostic of Hunter syndrome, provided other sulfatase deficiency has been ruled out [10]. Gene analysis for mutation may be used to confirm the diagnosis in male. Gene analysis is the only secure way to identify female carriers and could be used for prenatal diagnosis [5].

Enzyme replacement therapy using idursulfase (elaprase), a recombinant human enzyme produced in the human cell line, has been recently approved in the United States and the European Union for the management of MPS II [11]. Bone marrow transplantation and umbilical cord blood transplantation are definitive treatments for MPS. Apart from these, supportive management is very important. Physical therapy and daily exercise may improve mobility of joints. Blood transfusion, infection and nutritional management are also important in the management of MPS II.

\section{CONCLUSION}

Mucopolysaccharidosis is a multisystem disorder which presents with a constellation of various clinical findings. Hunter syndrome is a rare X-linked recessive disorder and is caused by deficiency of lysosomal enzyme iduronate-2-sulfatase. Careful and systemic approach is important for diagnosis of this disease.
Enzyme assay and urine GAGs level estimation are used for diagnosis. Definitive diagnosis is only made by gene analysis. Though definitive therapy is not available in all part of worlds, recombinant enzyme supplementation is important, promising aspect in management of this rare disease.

$* * * * * * * * *$

\section{Author Contributions}

Asutosh Biswas - Substantial contributions to conception and design, Acquisition of data, Analysis and interpretation of data, Drafting the article, Revising it critically for important intellectual content, Final approval of the version to be published

Prajowl Shrestha - Substantial contributions to conception and design, Acquisition of data, Analysis and interpretation of data, Drafting the article, Revising it critically for important intellectual content, Final approval of the version to be published

\section{Guarantor}

The corresponding author is the guarantor of submission.

\section{Conflict of Interest}

Authors declare no conflict of interest.

\section{Copyright}

(C) Asutosh Biswas et al. 2013; This article is distributed under the terms of Creative Commons Attribution 3.0 License which permits unrestricted use, distribution and reproduction in any means provided the original authors and original publisher are properly credited. (Please see www.ijcasereportsandimages.com/copyright-policy.php for more information.)

\section{REFERENCES}

1. Neufeld EF, Muenzer J. The mucopolysaccharidoses. In: Scriver CR, ed. The Metabolic and Molecular Bases of Inherited Disease. New York, NY: McGrawHill 2001:3421-52.

2. Baehner F, Schmiedeskamp C, Krummenauer F, et al. Cumulative incidence rates of the mucopolysaccharidoses in Germany. J Inherit Metab Dis 2005;28(6):1011-7.

3. Poorthuis BJ, Wevers RA, Kleijer WJ, et al. The frequency of lysosomal storage diseases in the Netherlands. Hum Genet 1999;105(1-2):151-6.

4. Meikle PJ, Hopwood JJ, Clague AE, Carey WF. 
Prevalence of lysosomal storage disorders. JAMA 1999;281(3):249-54.

5. Martin R, Beck M, Eng C, et al. Recognition and diagnosis of mucopolysaccharidosis II (Hunter syndrome). Pediatrics 2008;121(2):e377-86.

6. Hunter C. A rare disease in two brothers. Proc R Soc Med 1917;10:104-16.

7. Kliegman RM, Behrman RE, Jenson HB, Stanton FB. Nelson Textbook of Pediatrics. Volume 1. 18th edition. Philadel phia: Saunders 2007:620-6.

8. Tuschl K, Gal A, Paschke E, Kircher S, Bodamer OA. Mucopolysaccharidosis Type II in females: case report and review of literature. Pediatr Neurol 2005;32(4):270-2.
9. Daniele A, Di Natale P. Hunter Syndrome: Presence of material cross-reacting with antibodies against iduronate sulfatase. Human Genetics 1987;75(3):234-8.

10. Dean CJ, Bockmann MR, Hopwood JJ, Brooks DA, Meikle PJ. Detection of mucopolysaccharidosis type II by measurement of iduronate-2-sulfatase in dried blood spots and plasma samples. Clin Chem 2006;52(4):643-9.

11. Muenzer J, Wraith JE, Beck M, et al. A phase II/III clinical study of enzyme replacement therapy with idursulfase in mucopolysaccharidosis II (Hunter syndrome). Genet Med 2006;8(8):465-73.
Access full text article on other devices

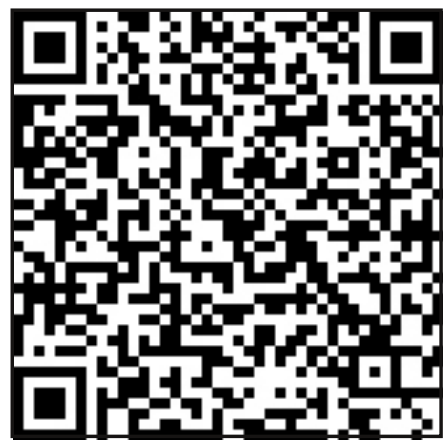

Access PDF of article on other devices

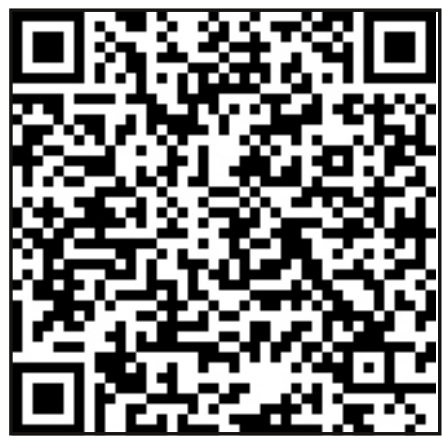

